Telemedicine journal and e-health, Nov 2011, Volume 17(9), pp712-21.

Oluseun Adeogun, Ashutosh Tiwari, Jeffrey R. Alcock,

\title{
Capabilities of Proprietary Intermediate Telehealth Devices
}

\begin{abstract}
Objective

Proprietary intermediate telehealth devices are those which are specifically designed as connectors between the entities of telehealth systems. This paper seeks to understand what are the capabilities of such devices and then to investigate how these are clustered on the current generation of devices.
\end{abstract}

\section{Materials and Methods}

14 current-generation devices available from 12 device providers were selected and analysed. Four categories of questions were composed to evaluate the devices: setup/configuration, available features, inputs and outputs.

\section{Results}

Data was collected and synthesised on the following capabilities: availability from suppliers, setup, environments of use, multiple-condition monitoring, multiuser capabilities, prompts, reminders and alerts, interaction with the health professional, access to historical data, device inputs and their transfer technology.

\section{Conclusions}

There are three main roles for proprietary intermediate devices in telehealth systems: displaying information to the patient; receiving data manually/automatically; forwarding results and questionnaire responses to another entity.

Provider perspective: Intermediate devices are usually part of closed proprietary systems. Providers produce disease-customisable devices. Connectivity is considerably ahead of the current generation of point-of-care devices. However, little data is available on connection to rest of the proprietary system.

Patient perspective: Clear benefit that one intermediate device can potentially be used with several chronic conditions. Simple setup, authentication procedures and automatic data transfer are key design aspects.

Health Professional perspective: Little direct interaction with the health professional. Payer perspective: Details of costs of devices are generally unavailable; system providers indicate cost variability is based on "user requirements". 


\section{Introduction}

Intermediate telehealth devices can be defined as connectors between entities of telehealth systems [1].

They fall into two classes. The first class is adapted devices which are those originally designed for other uses and have been adapted for telehealth systems, usually via integrating software into the device. These include mobile phones and personal computers (PC). The second class is proprietary devices, which, in contrast are those specifically designed for use in a telehealth system [1].

From a systems perspective, there is evidence that intermediate devices are the key invariant component in a telehealth system. A particular telehealth offering can be used for multiple diseases, and contain varied types of actors, but its intermediate device or devices are usually fixed: possessing particular sets of capabilities [1]. For this reason their capabilities form an important area of study.

\subsection{Previous case studies}

Some descriptions of the use of individual intermediate devices already exist in the literature. For example, Luptak et al., describe a study in which patient feedback was obtained on intermediate device used in daily chronic care [2].

Case-study evidence is also emerging that such devices can form part of systems that have tangible medical impact. Several PCTs (Primary Care Trusts) within the UK, have implemented telehealth systems incorporating intermediate devices. Examples include systems for patients with heart failure, and devices in systems to monitor chronic obstructive pulmonary disease (COPD) [3]. Device use in the latter has helped community nurses to prioritise their work, resulting in a decrease by $80 \%$ of home visits [3].

\subsection{The perspective of healthcare providers}

However, there has been no systematic study of the capabilities of current intermediate devices, nor of how those capabilities are clustered on current devices. From the perspective of those considering implementing telehealth systems for chronic care, this means that it is difficult to know whether their expectations could be met with current systems. For example, the answer to a question such as, can current telehealth systems monitor multiple diseases and if so what range of diseases can be covered, is dependent on whether the intermediate device of a system will connect with and process data from multiple point-of-care devices. Questions on how patients are monitored, prompted and advised are also dependant on the capabilities of intermediate devices. The same is true for questions of data security and confidentiality, key information capture and system usability.

\subsection{Research questions}

This paper assesses currently available intermediate devices in telehealth systems. 
It initially seeks to do two things. Firstly, to understand the capabilities of such devices. Secondly, to show how such capabilities are clustered on the current generation of devices.

Using this information it then seeks to summarise the capabilities of the devices as seen from an actor-centric viewpoint, i.e. the viewpoint of a potential patient, caregiver, health professional or payer. 


\section{Method}

\subsection{Criteria for selecting devices}

As little information is currently available on adapted devices, this study was limited to proprietary devices. It was also limited to devices which met the following criteria:

1. Devices that have a degree of certification i.e. FDA 510(k) or CE mark.

2. Devices that have been designed primarily for a patient rather than a health professional.

3. Devices that can be used outside the hospital environment.

Using these criteria, a total of 14 intermediate devices were analysed. Table 1 lists the devices evaluated, the organization using or distributing them, the type of certification and appropriate references.

\subsection{Data capture}

Proprietary devices available between November 2009 and April 2010 were analysed. Company websites and brochures were assessed to obtain information about the proprietary devices. Where there were insufficient details, the organizations were contacted requesting additional information and where necessary, a visit to the organisation was made. 


\begin{tabular}{|c|c|c|c|}
\hline Organization & Device name & Certifications & References \\
\hline $\begin{array}{l}\text { AxSys Technology } \\
\text { Ltd }\end{array}$ & $\begin{array}{l}\text { Exceliview (no } \\
\text { longer supported) }\end{array}$ & Could not be obtained & AxSys [4] \\
\hline $\begin{array}{l}\text { Bosch/Health Hero } \\
\text { Network }\end{array}$ & Health Buddy & $\begin{array}{l}\text { CE compliant; TUV US } \\
\text { \& C medical approved; } \\
\text { FDA } 510(\mathrm{k})\end{array}$ & $\begin{array}{l}\text { Health Hero Network } \\
\text { [5]; } \\
\text { FDA [6] }\end{array}$ \\
\hline Cardiocom & $\begin{array}{l}\text { Commander Home } \\
\text { monitor }\end{array}$ & FDA 510(k) & FDA [7] \\
\hline CareFusion & TeleAM & CE Mark; FDA & $\begin{array}{l}\text { Personal } \\
\text { communication, } \\
\text { Jürgen Behringer [8] }\end{array}$ \\
\hline Docobo & HealthHUB & $\begin{array}{l}\text { ISO 9002/EN46002 and } \\
\text { European Class Ila } \\
\text { Medical Device } \\
\text { standards }\end{array}$ & $\begin{array}{l}\text { Carson et al., [9]; } \\
\text { Docobo [10] }\end{array}$ \\
\hline $\mathrm{DigiO}_{2}$ & Care Pal & FDA 510(k) & $\begin{array}{l}\mathrm{DigiO}_{2}[11-12] \\
\mathrm{FDA}[13]\end{array}$ \\
\hline $\begin{array}{l}\text { Honeywell } \\
\text { International Inc/ } \\
\text { Home Telehealth } \\
\text { Ltd }\end{array}$ & $\begin{array}{l}\text { Honeywell } \\
\text { HomMed Genesis } \\
\text { DM }\end{array}$ & FDA 510(k) & $\begin{array}{l}\text { Honeywell [14]; } \\
\text { Home Telehealth Ltd } \\
{[15] ;} \\
\text { Advantage } \\
\text { HomeHealth Services } \\
{[16] ;} \\
\text { FDA [17] }\end{array}$ \\
\hline Intel & Health Guide & FDA 510(k) & Intel [18 - 19] \\
\hline MedApps & HealthPAL & FDA 510(k) & FDA [20] \\
\hline $\begin{array}{l}\text { Telehealth } \\
\text { solutions }\end{array}$ & Home pod & Could not be obtained & $\begin{array}{l}\text { Telehealth Solutions } \\
{[21-22]}\end{array}$ \\
\hline \multirow[t]{2}{*}{ Tunstall } & $\begin{array}{l}\text { mymedic } \\
\text { Telehealth Monitor }\end{array}$ & $\begin{array}{l}\text { CE Marked; Medical } \\
\text { Device directive }\end{array}$ & Tunstall [23-26] \\
\hline & $\begin{array}{l}\text { mymedic plus } \\
\text { Telehealth Monitor }\end{array}$ & FDA 510(k) & $\begin{array}{l}\text { Tunstall }[23-24], \\
{[26] ;} \\
\text { FDA [27] }\end{array}$ \\
\hline \multirow[t]{2}{*}{ Tynetec } & $\begin{array}{l}\text { Telehealth } \\
\text { interface unit }\end{array}$ & Could not be obtained & \multirow[t]{2}{*}{ Tynetec [28] } \\
\hline & SayPhone 21 & Could not be obtained & \\
\hline
\end{tabular}

Table 1 - Proprietary intermediate devices with data display capabilities. 


\subsection{Evaluation questions}

A set of questions were developed to evaluate proprietary intermediate devices. The questions correspond to four categories.

Setup/configuration: what is the required process to setup the intermediate device? (Table 2).

Available features: what are the features available on the intermediate device? (Table 3).

Inputs: how does the intermediate device receive its inputs? (Table 4).

Outputs: what are the outputs produced by the intermediate device? (Table 5).

\begin{tabular}{|l|l|}
\hline 1 1- Setup/configuration \\
\hline 1.1 & $\begin{array}{l}\text { Are you the only suppliers of the device or can it be purchased from } \\
\text { somewhere else? }\end{array}$ \\
\hline 1.2 & $\begin{array}{l}\text { Is the device provided to the patient as fully-functional i.e. plug-and-play or } \\
\text { is specific software required to make the device fully operational in the } \\
\text { system? }\end{array}$ \\
\hline 1.3 & Does the user need to create an online account to establish process? \\
\hline 1.4 & Do users need to explicitly configure the device? \\
\hline 1.6 & Which environment can the device be used (home only, anywhere)? \\
\hline
\end{tabular}

Table 2 - Criteria used to assess proprietary intermediate devices (Setup/configuration). 


\begin{tabular}{|c|c|}
\hline \multicolumn{2}{|c|}{ 2-Available features } \\
\hline 2.1 & What condition is the device designed to monitor? \\
\hline 2.2 & Can the device be customised to several health conditions? \\
\hline 2.3 & Is the device for single/multiple users? \\
\hline 2.4 & Does the device have voice prompts? \\
\hline 2.5 & Does the device have video capabilities? \\
\hline 2.6 & Does the device provide reminders? \\
\hline 2.7 & Does the device provide instructions of how to carry out the test? \\
\hline 2.8 & $\begin{array}{l}\text { Is the connection between the point-of-care device and intermediate device } \\
\text { a wired or wireless connection? }\end{array}$ \\
\hline 2.9 & List the type of connections in operation: Bluetooth, Infrared, Wi-Fi etc? \\
\hline 2.10 & $\begin{array}{l}\text { Is there a progress bar (or something similar) displayed on the device to } \\
\text { show that the user has sent their test results or they are in the process of } \\
\text { being received by the health professional? }\end{array}$ \\
\hline 2.11 & $\begin{array}{l}\text { Can the patient send a message to the health professional through the } \\
\text { device? }\end{array}$ \\
\hline 2.12 & Can the patient access historical data through the device? \\
\hline 2.13 & $\begin{array}{l}\text { Can the patient receive a message from the health professional through the } \\
\text { device? }\end{array}$ \\
\hline 2.14 & Are there authentication requirements before users can proceed with test? \\
\hline
\end{tabular}

Table 3 - Criteria used to assess proprietary intermediate devices (Available features).

3- Inputs

\begin{tabular}{|l|l|}
\hline 3.1 & What are the types of point-of-care devices that can be connected? \\
\hline $\mathbf{3 . 2}$ & $\begin{array}{l}\text { Is data transfer automatic from the point-of-care device to the intermediate } \\
\text { device or does the user have to manually enter the data? }\end{array}$ \\
\hline $\mathbf{3 . 3}$ & Does the device ask user symptomatic questions? \\
\hline $\mathbf{3 . 4}$ & $\begin{array}{l}\text { What is the mode of interaction between patient and device (touch screen, } \\
\text { button press etc)? }\end{array}$ \\
\hline $\mathbf{3 . 5}$ & Does the device confirm the user selection/entry? \\
\hline
\end{tabular}

Table 4 - Criteria used to assess proprietary intermediate devices (Inputs). 


\begin{tabular}{|l|l|}
\hline \multicolumn{2}{|l|}{ 4- Outputs } \\
\hline 4.1 & Where is the data from the device transferred to? \\
\hline 4.2 & $\begin{array}{l}\text { Are alerts provided to the patient on their result before they are sent to a } \\
\text { data repository? }\end{array}$ \\
\hline 4.3 & Do other users within the system receive an alert? \\
\hline 4.4 & What is the mode of delivering alerts? \\
\hline
\end{tabular}

Table 5 - Criteria used to assess proprietary intermediate devices (Outputs).

\subsection{Clustering}

In order to be able to see how capabilities are clustered in currently available intermediate devices, the clusters have been presented in the paper in tabulated form (Tables 6 to 19).

For each cluster table, the horizontal axis shows the device number in the study. The vertical axis shows the capabilities. Where a capability is present, a tick has been shown in the table; if absent, it has been shaded in black so that the clustering can easily be seen visually. Where the data were unobtainable, the corresponding position in the table has been left blank. Where additional coding of the data were required, this coding has been shown in a key below the table. 


\section{Results}

This section describes the findings of the analysis of proprietary intermediate devices based on the questions detailed in Tables 2-5. For each data set, where the data percentages do not add up to $100 \%$, the remaining data were unobtainable in this study.

Within each section of the results, there are two parts. The first part concerns individual capabilities of the devices: how often they are present and what is their nature. The second concerns how these individual capabilities are clustered on current devices.

\subsection{Availability}

93\% of intermediate devices are purchasable from a single provider while $7 \%$ (device 5) are available from multiple providers (3 suppliers in total).

As shown in Table 6, much less information was available from manufacturers on devices provided within a system with $79 \%$ of data being unavailable. $21 \%$ of devices are sold for use within a system package. Within this group, one device (device 8) can also be bought off the shelf. Device 5, available from multiple suppliers, is only sold for use within a system package.

Cost information was generally unavailable from the manufacturers. Manufacturers indicated that costs varied with quantity and with user requirements.

\begin{tabular}{|c|c|c|c|c|c|c|c|c|c|c|c|c|c|c|}
\hline & 1 & 2 & 3 & 4 & 5 & 6 & 7 & 8 & 9 & 10 & 11 & 12 & 13 & 14 \\
\hline $\begin{array}{c}\text { Single } \\
\text { supplier }\end{array}$ & $\checkmark$ & $\checkmark$ & $\checkmark$ & $\checkmark$ & & $\checkmark$ & $\checkmark$ & $\checkmark$ & $\checkmark$ & $\checkmark$ & $\checkmark$ & $\checkmark$ & $\checkmark$ & $\checkmark$ \\
\hline $\begin{array}{l}\text { Multiple } \\
\text { suppliers }\end{array}$ & & & & & $\checkmark$ & & & & & & & & & \\
\hline $\begin{array}{c}\text { Device sold } \\
\text { as part of a } \\
\text { system } \\
\text { package }\end{array}$ & $\checkmark$ & & & & $\checkmark$ & & & $\checkmark$ & & & & & & \\
\hline $\begin{array}{c}\text { Device can } \\
\text { be bought } \\
\text { off the shelf }\end{array}$ & & & & & & & & $\checkmark$ & & & & & & \\
\hline $\begin{array}{c}\text { Cost of } \\
\text { device }(f)\end{array}$ & V & & & & V & & & 1000 & & & & & $\mathrm{~V}$ & V \\
\hline
\end{tabular}

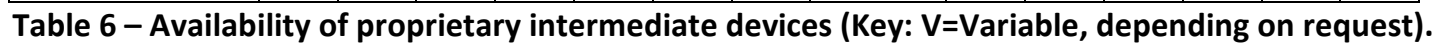

\subsection{Setup}

Devices neither require explicit configuration by the patient, nor establishment of any on-line account (though information was unavailable in $21 \%$ and $29 \%$ of cases respectively). 


\subsection{Environments}

$14 \%$ of intermediate devices can be used in both home and hospital, $50 \%$ are exclusively for home use and $36 \%$ can be used in any location.

Table 7 shows the clustering of intended device environments. All devices that were usable outside the home and hospital environment were also designed for use in that environment.

\begin{tabular}{|l|c|c|c|c|c|c|c|c|c|c|c|c|c|c|}
\hline & $\mathbf{1}$ & $\mathbf{2}$ & $\mathbf{3}$ & $\mathbf{4}$ & $\mathbf{5}$ & $\mathbf{6}$ & $\mathbf{7}$ & $\mathbf{8}$ & $\mathbf{9}$ & $\mathbf{1 0}$ & $\mathbf{1 1}$ & $\mathbf{1 2}$ & $\mathbf{1 3}$ & $\mathbf{1 4}$ \\
\hline Home & $\checkmark$ & $\checkmark$ & $\checkmark$ & $\checkmark$ & $\checkmark$ & $\checkmark$ & $\checkmark$ & $\checkmark$ & $\checkmark$ & $\checkmark$ & $\checkmark$ & $\checkmark$ & $\checkmark$ & $\checkmark$ \\
\hline Hospital & $\checkmark$ & & $\checkmark$ & $\checkmark$ & & $\checkmark$ & $\checkmark$ & $\checkmark$ & & & & & $\checkmark$ & \\
\hline Other & & & & $\checkmark$ & & $\checkmark$ & $\checkmark$ & $\checkmark$ & & & & & $\checkmark$ & \\
\hline
\end{tabular}

Table 7 - Environments in which proprietary intermediate devices can be used.

\subsection{Multiple conditions and point-of-care connection options}

All of the intermediate devices evaluated can be customised to manage several health conditions including: asthma, COPD, diabetes, heart disease and hypertension. $21 \%$ of devices were said to be used for managing unspecified "chronic conditions".

Table 8 shows the clustering of conditions by device. The majority of devices are used for a cluster of four diseases, COPD, diabetes, heart disease and hypertension. In contrast, asthma is much less well served.

\begin{tabular}{|l|l|l|l|l|l|l|l|l|l|l|l|l|l|l|}
\hline & $\mathbf{1}$ & $\mathbf{2}$ & $\mathbf{3}$ & $\mathbf{4}$ & $\mathbf{5}$ & $\mathbf{6}$ & $\mathbf{7}$ & $\mathbf{8}$ & $\mathbf{9}$ & $\mathbf{1 0}$ & $\mathbf{1 1}$ & $\mathbf{1 2}$ & $\mathbf{1 3}$ & $\mathbf{1 4}$ \\
\hline $\begin{array}{l}\text { Can be customised } \\
\text { to several health } \\
\text { conditions }\end{array}$ & $\checkmark$ & $\checkmark$ & $\checkmark$ & $\checkmark$ & $\checkmark$ & $\checkmark$ & $\checkmark$ & $\checkmark$ & $\checkmark$ & $\checkmark$ & $\checkmark$ & $\checkmark$ & $\checkmark$ & $\checkmark$ \\
\hline Asthma & $\checkmark$ & $\checkmark$ & & & & $\checkmark$ & & $\checkmark$ & & & & & $\checkmark$ \\
\hline COPD & $\checkmark$ & $\checkmark$ & $\checkmark$ & $\checkmark$ & & $\checkmark$ & $\checkmark$ & $\checkmark$ & $\checkmark$ & & $\checkmark$ \\
\hline Diabetes & $\checkmark$ & $\checkmark$ & & $\checkmark$ & $\checkmark$ & $\checkmark$ & $\checkmark$ & $\checkmark$ & & $\checkmark$ \\
\hline Heart disease & $\checkmark$ & $\checkmark$ & $\checkmark$ & & $\checkmark$ & $\checkmark$ & $\checkmark$ & $\checkmark$ & $\checkmark$ \\
\hline Hypertension & $\checkmark$ & $\checkmark$ & $\checkmark$ & $\checkmark$ & $\checkmark$ & $\checkmark$ & $\checkmark$ & $\checkmark$ & $\checkmark$ & $\checkmark$ \\
\hline $\begin{array}{l}\text { Unspecified } \\
\text { chronic condition }\end{array}$ & & & $\checkmark$ & & & & & & & & & $\checkmark$ & $\checkmark$ \\
\hline
\end{tabular}

Table 8 - Chronic conditions managed by proprietary intermediate devices. (Where the chronic condition is shown as unspecified, this means that the organization did not describe the condition).

93\% of intermediate devices evaluated allow multiple point-of-care devices to be connected to them. The remaining $7 \%$ of intermediate devices obtain their data from another intermediate device. Point-of-care devices include: glucometers, weighing 
scales, blood pressure (BP) monitors, pulse oximeters, spirometers and peak flow meters.

Table 9 shows the different types of point-of-care devices providing inputs to intermediate devices. The most popular were BP monitor, weighing scale, glucometer and pulse oximeter. The less popular ones were peak flow meter and spirometer. The coagulometer and urine analyser were least represented.

\begin{tabular}{|l|c|c|c|c|c|c|c|c|c|c|c|c|c|c|}
\hline & $\mathbf{1}$ & $\mathbf{2}$ & $\mathbf{3}$ & $\mathbf{4}$ & $\mathbf{5}$ & $\mathbf{6}$ & $\mathbf{7}$ & $\mathbf{8}$ & $\mathbf{9}$ & $\mathbf{1 0}$ & $\mathbf{1 1}$ & $\mathbf{1 2}$ & $\mathbf{1 3}$ & $\mathbf{1 4}$ \\
\hline BP monitor & $\checkmark$ & $\checkmark$ & & $\checkmark$ & $\checkmark$ & $\checkmark$ & $\checkmark$ & $\checkmark$ & $\checkmark$ & $\checkmark$ & $\checkmark$ & & $\checkmark$ & $\checkmark$ \\
\hline Weighing scale & & $\checkmark$ & $\checkmark$ & $\checkmark$ & $\checkmark$ & & $\checkmark$ & $\checkmark$ & $\checkmark$ & $\checkmark$ & $\checkmark$ & & $\checkmark$ & $\checkmark$ \\
\hline Glucometer & $\checkmark$ & $\checkmark$ & $\checkmark$ & $\checkmark$ & $\checkmark$ & & $\checkmark$ & $\checkmark$ & $\checkmark$ & $\checkmark$ & $\checkmark$ & & & \\
\hline Pulse oximeter & & $\checkmark$ & & & $\checkmark$ & $\checkmark$ & $\checkmark$ & $\checkmark$ & $\checkmark$ & $\checkmark$ & $\checkmark$ & & $\checkmark$ & $\checkmark$ \\
\hline Peak flow meter & $\checkmark$ & $\checkmark$ & & $\checkmark$ & $\checkmark$ & & & & $\checkmark$ & & & & & \\
\hline Spirometer & & & & & & $\checkmark$ & & & & $\checkmark$ & $\checkmark$ & & & \\
\hline Coagulometer & & & & & & & & $\checkmark$ & & & & & & \\
\hline Urine analyser & & & & & & & & $\checkmark$ & & & & & & \\
\hline
\end{tabular}

Table 9 - Types of point-of-care devices providing inputs for proprietary intermediate devices.

\subsection{Multiple Users}

$36 \%$ of intermediate devices are designed for the use of multiple users; and $64 \%$ by only a single user (Table 10).

\begin{tabular}{|l|l|l|l|l|l|l|l|l|l|l|l|l|l|l|}
\hline & 1 & 2 & 3 & 4 & 5 & 6 & 7 & 8 & 9 & 10 & 11 & 12 & 13 & 14 \\
\hline $\begin{array}{l}\text { Device is for } \\
\text { multiple users }\end{array}$ & $\checkmark$ & & & & & $\checkmark$ & & & $\checkmark$ & & & $\checkmark$ & & $\checkmark$ \\
\hline
\end{tabular}

Table 10 - Proprietary intermediate devices designed for multiple users.

\subsection{Prompts, Reminders and Confirmations}

Voice prompts are available on $64 \%$ of devices, $29 \%$ do not have this feature.

$86 \%$ of intermediate devices provide reminders to users, $7 \%$ do not.

In cases where users enter data or select an option on the intermediate device, $36 \%$ display a confirmation to the user of the selected option, $21 \%$ do not.

$64 \%$ of intermediate devices ask the user symptomatic questions, whereas $29 \%$ do not.

$50 \%$ of intermediate devices display a confirmation to the user that their results have been transferred to the health professional, $21 \%$ do not. This confirmation took the form of a progress bar or a message displayed to the user.

Table 11 shows the clustering of the prompts capabilities of intermediate devices. 


\begin{tabular}{|l|c|c|c|c|c|c|c|c|c|c|c|c|c|c|}
\hline & $\mathbf{1}$ & $\mathbf{2}$ & $\mathbf{3}$ & $\mathbf{4}$ & $\mathbf{5}$ & $\mathbf{6}$ & $\mathbf{7}$ & $\mathbf{8}$ & $\mathbf{9}$ & $\mathbf{1 0}$ & $\mathbf{1 1}$ & $\mathbf{1 2}$ & $\mathbf{1 3}$ & $\mathbf{1 4}$ \\
\hline $\begin{array}{l}\text { Has voice } \\
\text { prompts }\end{array}$ & & $\checkmark$ & $\checkmark$ & & $\checkmark$ & & $\checkmark$ & $\checkmark$ & $\checkmark$ & $\checkmark$ & $\checkmark$ & $\checkmark$ & & \\
\hline $\begin{array}{l}\text { Provides } \\
\text { reminders }\end{array}$ & $\checkmark$ & & $\checkmark$ & $\checkmark$ & $\checkmark$ & $\checkmark$ & $\checkmark$ & $\checkmark$ & $\checkmark$ & $\checkmark$ & $\checkmark$ & $\checkmark$ & $\checkmark$ \\
\hline Asks questions & & $\checkmark$ & & $\checkmark$ & $\checkmark$ & $\checkmark$ & & $\checkmark$ & $\checkmark$ & $\checkmark$ & $\checkmark$ & & $\checkmark$ & \\
\hline $\begin{array}{l}\text { Confirmation of } \\
\text { the user } \\
\text { selection/ entry }\end{array}$ & & & & $\checkmark$ & & & & $\checkmark$ & & $\checkmark$ & $\checkmark$ & & $\checkmark$ \\
\hline $\begin{array}{l}\text { Confirmation of } \\
\text { transmission of } \\
\text { results }\end{array}$ & $\checkmark$ & & & $\checkmark$ & $\checkmark$ & & $\checkmark$ & & & $\checkmark$ & $\checkmark$ & & $\checkmark$ \\
\hline
\end{tabular}

Table 11 - Prompts available on proprietary intermediate devices.

\subsection{Alerts}

Alerts are provided directly to patients in $29 \%$ of intermediate devices (Table 12); while $64 \%$ of devices do not provide alerts to patients. In each case this is in the form of messages displayed on the intermediate device informing the user that their result is not within the expected target range.

\begin{tabular}{|c|c|c|c|c|c|c|c|c|c|c|c|c|c|c|}
\hline & 1 & 2 & 3 & 4 & 5 & 6 & 7 & 8 & 9 & 10 & 11 & 12 & 13 & 14 \\
\hline $\begin{array}{l}\text { Alerts on results to } \\
\text { patient before they } \\
\text { are sent to a data } \\
\text { repository }\end{array}$ & & & & $\checkmark$ & & & & & & $\checkmark$ & $\checkmark$ & & $\checkmark$ & \\
\hline
\end{tabular}

Table 12 - Alerts to patients on proprietary intermediate devices.

\subsection{Advice, and Communication with the Health professional}

$57 \%$ of intermediate devices provide instructions to the user as to how to carry out a particular test, $21 \%$ do not. In one device (device 5 ), training videos are provided for the user.

No device was found to have the capability for patients to send additional messages to their doctor (though information was unavailable for $29 \%$ of cases).

One device (device 12) allows an alarm call to be made to the doctor.

Health professionals are alerted when the patients' results are outside specified thresholds. (However, none of these alerts are through the intermediate device.)

$29 \%$ of intermediate devices enable patients to receive messages from the health professionals compared with $42 \%$ that do not have this feature. In one of the devices (device 5), a 2-way video call can be organised by the health professional to discuss issues with the patients. Table 13 shows the device capabilities for advice and communication. 


\begin{tabular}{|c|c|c|c|c|c|c|c|c|c|c|c|c|c|c|}
\hline & 1 & 2 & 3 & 4 & 5 & 6 & 7 & 8 & 9 & 10 & 11 & 12 & 13 & 14 \\
\hline $\begin{array}{l}\text { Provides } \\
\text { instructions of how } \\
\text { to carry out test }\end{array}$ & & & & $\checkmark$ & $\checkmark$ & & & $\checkmark$ & $\checkmark$ & $\checkmark$ & $\checkmark$ & $\checkmark$ & & $\checkmark$ \\
\hline $\begin{array}{l}\text { Has video } \\
\text { capabilities }\end{array}$ & & & & & $\checkmark$ & & & $\checkmark$ & & & & & & \\
\hline $\begin{array}{l}\text { Patient can send a } \\
\text { message to the } \\
\text { health professional }\end{array}$ & & & & & $\ldots$ & 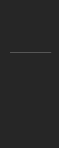 & - & 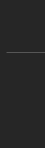 & 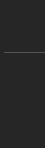 & - & & 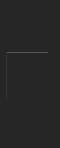 & $\square$ & \\
\hline $\begin{array}{l}\text { Patient can receive } \\
\text { a message from } \\
\text { the health } \\
\text { professional }\end{array}$ & & & & & $\checkmark$ & $\checkmark$ & & $\checkmark$ & & 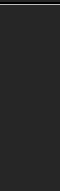 & & & $\checkmark$ & \\
\hline
\end{tabular}

Table 13 - Advice provided to users on proprietary intermediate devices.

\subsection{Historical data}

Patients can access historical data on the device in $36 \%$ of intermediate devices (devices $1,5,6,8,13$ ) compared with $43 \%$ that do not provide this feature.

\subsection{Authentication}

$29 \%$ of intermediate devices (devices $1,5,8,13$ ) require authentication by the users, although this feature requires activation; $50 \%$ do not require this.

\subsection{Automatic or manual results input}

Results of point-of-care tests are automatically transferred from the point-of-care device to the intermediate devices in $50 \%$ of cases. Results are manually entered in $7 \%$ of devices. In $29 \%$ of devices, results transfer is both automatic and manual.

Table 14Error! Reference source not found. shows the clustering of results transfer based on mode of input.

\begin{tabular}{|l|l|l|l|l|l|l|l|l|l|l|l|l|l|l|}
\hline & $\mathbf{1}$ & $\mathbf{2}$ & $\mathbf{3}$ & $\mathbf{4}$ & $\mathbf{5}$ & $\mathbf{6}$ & $\mathbf{7}$ & $\mathbf{8}$ & $\mathbf{9}$ & $\mathbf{1 0}$ & $\mathbf{1 1}$ & $\mathbf{1 2}$ & $\mathbf{1 3}$ & $\mathbf{1 4}$ \\
\hline $\begin{array}{l}\text { Manual data entry } \\
\text { into the device }\end{array}$ & $\checkmark$ & & & $\checkmark$ & $\checkmark$ & $\checkmark$ & & & $\checkmark$ & & & & & \\
\hline $\begin{array}{l}\text { Automated data } \\
\text { entry into the } \\
\text { device }\end{array}$ & & & & $\checkmark$ & $\checkmark$ & $\checkmark$ & $\checkmark$ & $\checkmark$ & $\checkmark$ & $\checkmark$ & $\checkmark$ & $\checkmark$ & $\checkmark$ & $\checkmark$ \\
\hline
\end{tabular}

Table 14 - Automatic or manual results input for proprietary intermediate devices.

\subsection{Device Inputs}

The inputs for the intermediate devices are either data from point-of-care devices and/or responses to questionnaires to help assess the symptoms of the patient. 79\% of intermediate devices allow patients to interact with them through buttons, $14 \%$ had a touch screen interface.

Table 15Error! Reference source not found. shows the availability of these features. 


\begin{tabular}{|l|l|l|l|l|l|l|l|l|l|l|l|l|l|l|}
\hline & $\mathbf{1}$ & $\mathbf{2}$ & $\mathbf{3}$ & $\mathbf{4}$ & $\mathbf{5}$ & $\mathbf{6}$ & $\mathbf{7}$ & $\mathbf{8}$ & $\mathbf{9}$ & $\mathbf{1 0}$ & $\mathbf{1 1}$ & $\mathbf{1 2}$ & $\mathbf{1 3}$ & $\mathbf{1 4}$ \\
\hline $\begin{array}{l}\text { Buttons } \\
\text { available for } \\
\text { patient to } \\
\text { interact with } \\
\text { the device }\end{array}$ & $\checkmark$ & $\checkmark$ & & $\checkmark$ & & $\checkmark$ & $\checkmark$ & & $\checkmark$ & $\checkmark$ & $\checkmark$ & $\checkmark$ & $\checkmark$ & $\checkmark$ \\
\hline $\begin{array}{l}\text { Touch screen } \\
\text { available for } \\
\text { patient to } \\
\text { interact with } \\
\text { the device }\end{array}$ & & & & & & & & & & & & & & \\
\hline
\end{tabular}

Table 15 - Proprietary intermediate device inputs.

\subsection{Information transfer technology}

To transfer results to the intermediate device from a point-of-care device, $64 \%$ of devices provide both wired and wireless connections, $21 \%$ provide only a wireless connection. The wireless connections include: Bluetooth, GPRS (General Packet Radio Service), infrared, radio, GSM (Global System for Mobile Communications), M2M (Mobile to mobile) Cellular GPS and Wi-Fi. The wired connections are through USB or serial cables.

Table 16 shows the details of the wired connections from the point-of-care device to intermediate device with the serial port being the most popular.

Table 17shows the details of the wireless connections from the point-of-care device to the intermediate device, with Bluetooth being the most widely used.

Table 18 shows the information transfer technology in operation between the devices and other components of telehealth systems. As can be seen, few providers made this information available. There is no pattern in the types of information transfer technology used, although GPRS was used by three devices $(2,8$, and 9$)$.

\begin{tabular}{|l|c|c|c|c|c|c|c|c|c|c|c|c|c|c|}
\hline & $\mathbf{1}$ & $\mathbf{2}$ & $\mathbf{3}$ & $\mathbf{4}$ & $\mathbf{5}$ & $\mathbf{6}$ & $\mathbf{7}$ & $\mathbf{8}$ & $\mathbf{9}$ & $\mathbf{1 0}$ & $\mathbf{1 1}$ & $\mathbf{1 2}$ & $\mathbf{1 3}$ & $\mathbf{1 4}$ \\
\hline $\begin{array}{l}\text { Wired connection to } \\
\text { point-of-care device }\end{array}$ & $\checkmark$ & & & $\checkmark$ & $\checkmark$ & & $\checkmark$ & $\checkmark$ & $\checkmark$ & $\checkmark$ & $\checkmark$ & & $\checkmark$ & \\
\hline $\begin{array}{l}\text { Serial Port } \\
\text { connections }\end{array}$ & $\checkmark$ & & & $\checkmark$ & & & $\checkmark$ & $\checkmark$ & $\checkmark$ & $\checkmark$ & $\checkmark$ & & $\checkmark$ & \\
\hline USB & $\checkmark$ & & & & $\checkmark$ & & & $\checkmark$ & & & & & $\checkmark$ & \\
\hline
\end{tabular}

Table 16 - Wired information transfer technology between point-of-care devices and proprietary intermediate devices. 


\begin{tabular}{|l|c|c|c|c|c|c|c|c|c|c|c|c|c|c|}
\hline & $\mathbf{1}$ & $\mathbf{2}$ & $\mathbf{3}$ & $\mathbf{4}$ & $\mathbf{5}$ & $\mathbf{6}$ & $\mathbf{7}$ & $\mathbf{8}$ & $\mathbf{9}$ & $\mathbf{1 0}$ & $\mathbf{1 1}$ & $\mathbf{1 2}$ & $\mathbf{1 3}$ & $\mathbf{1 4}$ \\
\hline $\begin{array}{l}\text { Wireless } \\
\text { connection to } \\
\text { point-of-care } \\
\text { device }\end{array}$ & $\checkmark$ & & $\checkmark$ & $\checkmark$ & $\checkmark$ & $\checkmark$ & $\checkmark$ & & $\checkmark$ & $\checkmark$ & $\checkmark$ & $\checkmark$ & $\checkmark$ \\
\hline Bluetooth & $\checkmark$ & & & $\checkmark$ & $\checkmark$ & & $\checkmark$ & $\checkmark$ & & $\checkmark$ & $\checkmark$ & & $\checkmark$ & \\
\hline Infra red & & & & $\checkmark$ & & & & & & $\checkmark$ & $\checkmark$ & & & \\
\hline Radio & & & & & & & & & & & & $\checkmark$ & & $\checkmark$ \\
\hline
\end{tabular}

Table 17 - Wireless information transfer technology between point-of-care devices and proprietary intermediate devices.

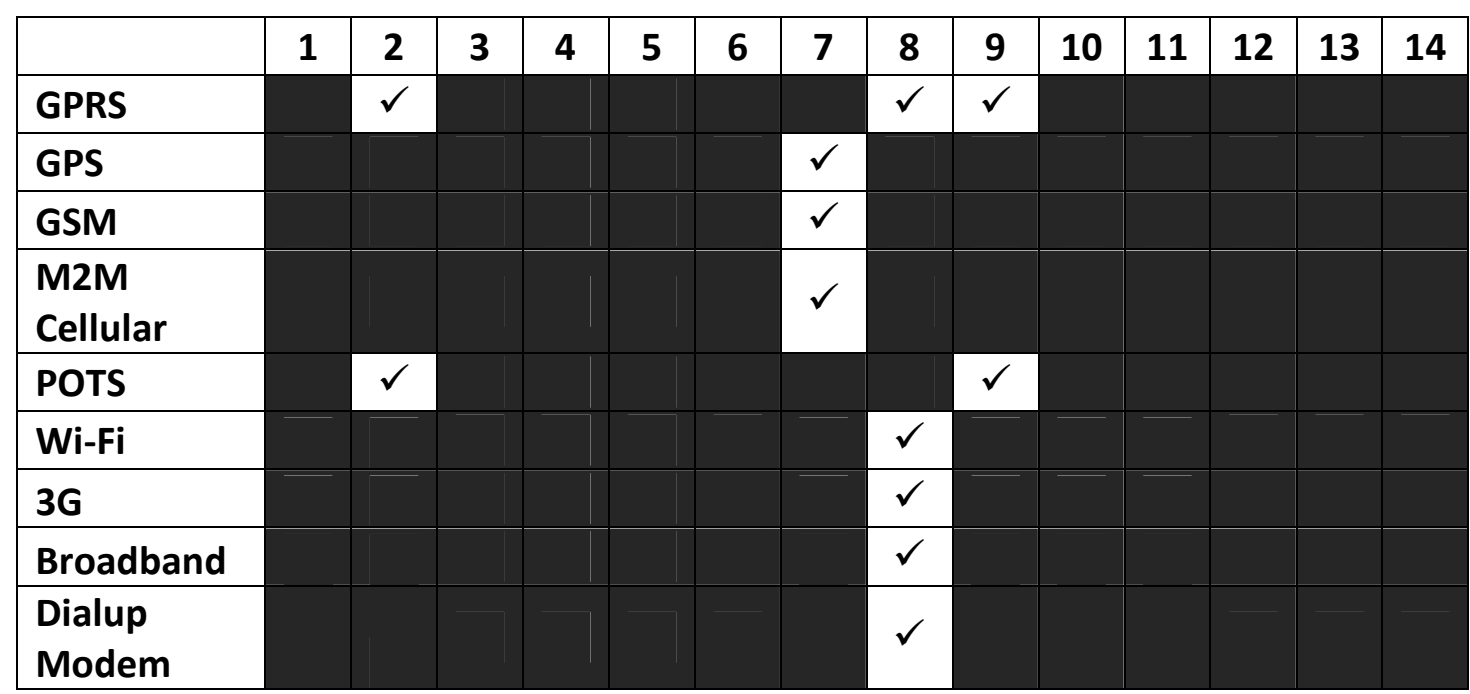

Table 18 - Information transfer technology between proprietary intermediate devices and other components of telehealth systems.

\subsection{Data transfer destination.}

Results and responses to the questions are transferred to: a software application (29\%) a secure server (57\%) or another intermediate device (7\%).

Table 19 shows the breakdown by device.

\begin{tabular}{|c|c|c|c|c|c|c|c|c|c|c|c|c|c|c|}
\hline & 1 & 2 & 3 & 4 & 5 & 6 & 7 & 8 & 9 & 10 & 11 & 12 & 13 & 14 \\
\hline $\begin{array}{l}\text { Data is transferred } \\
\text { to a data server }\end{array}$ & $\checkmark$ & $\checkmark$ & & $\checkmark$ & $\checkmark$ & $\checkmark$ & $\checkmark$ & $\checkmark$ & & & & & $\checkmark$ & \\
\hline $\begin{array}{l}\text { Data is transferred } \\
\text { to a software } \\
\text { application }\end{array}$ & & & & & 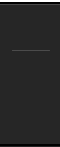 & & - & 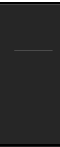 & $\checkmark$ & $\checkmark$ & $\checkmark$ & $\checkmark$ & & \\
\hline $\begin{array}{l}\text { Data is transferred } \\
\text { to an intermediate } \\
\text { device }\end{array}$ & & & & & & & & & & & & & & $\checkmark$ \\
\hline
\end{tabular}

Table 19 - Data transfer destination for intermediate devices 


\section{Discussion}

In this section, the key capabilities and their variance on current proprietary intermediate devices are summarised. Capabilities of proprietary devices are then considered based on actor-centric perspectives, i.e. those of the patient, health professional and payer and system provider. It should be noted that a caregiver perspective is not given, as no interactions of the devices with caregivers were found.

\subsection{Key capabilities of current proprietary intermediate devices}

Three main types of capability were identified from the current analysis.

Firstly: to display information to patients. These are reminders, instructions of how to conduct tests, symptomatic questions and confirmation of their entry or the successful transmission of results to another entity. Most proprietary devices provided reminders and asked the patient questions. Just over half of proprietary devices showed users how to do their test. Half of proprietary devices showed a confirmation of results transmission, while few confirmed the user entry.

Secondly: to act as a channel which receives results, automatically from point-of-care devices or manually via data entry by the patient. Half of devices allowed automatic input of results, while few allowed manual results entry.

Thirdly: to act as a channel for the forwarding of results and questionnaire responses to another entity. This may be another intermediate device, external server or software application. Most proprietary devices transferred results to an external server.

\subsection{Provider perspective}

By definition all the devices evaluated in this study were for use in the home. In a study by Hopp et al., showing the management of diabetes, the devices were only used within the home environment, however, providers consider multiple environments to be a market, as more than one third of devices were also suitable for hospital use [29].

Devices are clearly provider-specific, with only a single device being available from multiple suppliers. From the limited information available, providers appear keen on selling a whole system package; only one device is available off the shelf. The stateof-the-art is therefore that intermediate devices are usually part of closed proprietary systems.

All of the intermediate devices evaluated can be customised to manage several health conditions with the majority of devices usable for a cluster of four diseases: COPD, diabetes, heart disease and hypertension. Hence, nearly all intermediate devices are designed for connection to more than one point-of-care device. Point-ofcare devices that can be connected include: glucometers, weighing scales, blood pressure (BP) monitors, pulse oximeters, spirometers and peak flow meters.

This requirement for point-of-care device connectivity leads to information being widely available from suppliers on information technology for data transfer from point-of-care device to intermediate device. Nearly all intermediate devices allow 
transfer using both wired and wireless media. In contrast little data is available as to how the intermediate device connects to rest of the proprietary system.

Interestingly, the multiple connectivity features of intermediate devices, for use to connect with point-of-care devices, contrast with current point-of-care devices. Results from a recent study focussing on glucometers showed that only $51 \%$ allowed the data to be transferred. Of these, the majority (90\%) used a USB cable, while $10 \%$ used infra-red connection [30]. None used any other wireless technology.

Providers seem divided as to whether single-user or multiple-user intermediate devices will gain them market share, with only a third of devices being multi-user capable. Aside from the opportunity to sell more devices, if each device is only for a single user, providers may consider that this device limitation reduces requirements for setup and authentication and helps with data security for the patient.

Providers also appear to be currently divided as to the necessity of either voice or video technology. Voice prompts were present on over half the intermediate devices, but video technology was available on only one. The case for the utility of video technology in intermediate devices seems yet to be made.

In contrast, providers are essentially unanimous in device designs which exclude the initiation of direct communication with a health professional by the patient.

\subsection{Patient perspective}

Providers appear keen to minimise the information technology knowledge required of the patient. For the patient this translates to simple setup and authentication procedures (few devices had any authentication) and automatic data transfer from the point-of-care device to the intermediate device. Perhaps this is also a reason why only a third of devices allow patients access to historical data.

Less than a third of devices enable patients to receive messages from the health professionals with one device allowing a two-way video call initiated by the health professional.

With regards to device interaction with patients, nearly all devices provide reminders to patients; over two thirds are capable of quizzing patients about their symptoms. The majority of devices also provided test instructions. In contrast, the figure for point-of-care devices (glucometers) for reminders is 19\% [30]. This difference indicates where intermediate devices can bring benefits in patient independence and compliance above those available from the current generation of point of care devices.

In contrast, few intermediate devices are designed to provide alerts, for example following an unexpected result. An anecdotal reason, given by some suppliers, is to avoid raising false alarms. However, this compares with, again taking glucometers as examples of point of care devices, to $77 \%$ percent that do provide alerts [30].

Certain chronic diseases are risk factors for others, for example, diabetes for cardiovascular disease, cerebrovascular disease and renal disease [31]. Therefore, it is a clear benefit from the patient perspective that one intermediate device can potentially be used with several chronic conditions. 


\subsection{Health professional perspective}

Unlike for the case of the patient, intermediate devices have little direct contact with the health professional: the health professional sees aspects of the system rather than the intermediate device.

The main role of health professionals in relation to the intermediate device is that of selecting the types of questionnaires that will be used to regularly assess the patient's health. This role of health professionals is echoed by Hopp et al., where questions are specifically configured for patients [29]. Hopp et al., added that health professionals trained patients in how to use the device to collate their responses [29]. The aspect of training patients was not investigated in this paper.

\subsection{Payer Perspective}

The detail of cost of devices was generally unavailable and system providers indicated the variability of the cost of systems is based on user requirements. Since devices are provided as part of a telehealth solution it is usually the cost of the system that the payer sees.

Whilst providers see multiple chronic disease capabilities as a selling point, anecdotal evidence from one provider indicates that payers are initially interested in buying provision for a single chronic disease.

\subsection{Limitations}

In order to predict the directions of future development of proprietary devices, an extensive survey would need to be carried out to ascertain the expectations of the actors as to the additional features they need.

There is very limited data and analysis available in the literature on proprietary intermediate devices. Hence it is difficult to compare and contrast the data and analysis of this paper with the work of other researchers. 


\section{Conclusions}

Proprietary intermediate telehealth devices are those which are specifically designed as connectors between the entities of telehealth systems.

In this paper their capabilities have been analysed in current telehealth systems for the management of chronic diseases.

From the perspective of the different actors concerned with telehealth systems the following can be concluded:

Provider perspective: Intermediate devices are usually part of closed proprietary systems, i.e. they are provider-specific and normally sold as part of a whole system package. Providers produce disease-customisable devices, capable of connection to more than one point-of-care device via wired and multiple wireless media; their connectivity is considerably ahead of the current generation of point-of-care devices. In contrast little data is available from providers on how the intermediate device connects to rest of the proprietary system. Providers currently design the majority of devices for a single-user.

Patient perspective: Simple setup and authentication procedures (few devices had any authentication) and automatic data transfer from the point-of-care device to the intermediate device seem key aspects of device design for patients. The majority of devices provide reminders to patients, quiz patients about their symptoms and provide test instructions; this contrasts with current point-of-care devices. However, few intermediate devices are designed to provide alerts, again in contrast to pointof-care devices. For the patient there is a clear benefit that one intermediate device can potentially be used with several chronic conditions.

Health Professional perspective: Proprietary intermediate devices have little direct interaction with the health professional: their current main role is restricted to selecting the types of questionnaires that will be used to assess the patient's health. Payer perspective: The details of costs of devices were generally unavailable and system providers indicated the variability of the cost of systems is based on user requirements. Since devices are provided as part of a telehealth solution it is usually the cost of the system that the payer sees. 


\section{Acknowledgements}

The authors acknowledge the EPSRC and Cranfield IMRC for funding this research

\section{Author Disclosure Statement}

No competing financial interests exist.

\section{References}

1. Adeogun O, Tiwari A and Alcock JR. Models of information exchange for UK telehealth systems. International journal of medical informatics 2011;80:5:359-370

2. Luptak M, Dailey N, Juretic M, Rupper R, Hill RD, Hicken BL and Bair BD. The Care Coordination Home Telehealth (CCHT) rural demonstration project: a symptombased approach for serving older veterans in remote geographical settings. Rural and remote health 2010;10:2:1375

3. Marshall M. Monitoring long term conditions with Telehealth. British journal of community nursing, 2009;14:6:246-248

4. AxSys Technology Ltd. Exceliview. c2005 [cited 2010 December 15]. Available from: http://www.axsys.co.uk/clinical devices.htm

5. Health Hero Network. Health Buddy ${ }^{\circledR}$ Appliance. c2008 [cited 2010 December 15]. Available from: https://www.healthhero.com/pdf files/SpecSheet3.pdf

6. FDA (Food and Drug Administration). Health Buddy 510(k) Premarket Notification. (2010e). c2010 [updated 2010 July 12; cited 2010 December 15]. Available from: http://www.accessdata.fda.gov/scripts/cdrh/cfdocs/cfpmn/PMNSimpleSearch.cfm?s earch term=health\%20and\%20buddy\&PAGENUM=10\&sort=approvaldateasc

7. FDA (Food and Drug Administration). Commander 111, 510(k) Premarket Notification. (2010d). c2010 [updated 2010 July 12; cited 2010 December 22]. Available

from: http://www.accessdata.fda.gov/scripts/cdrh/cfdocs/cfpmn/PMNSimpleSearch.cfm? $\mathrm{db}=P M N \& i d=K 091821$

8. Personal Communication, Jürgen Behringer, Senior Director, CareFusion. (2010 May 11)

9. Carson ER, Cramp DG, Flowerday A, Harrar H, Harvey FE, Leicester HJ and Roudsari AV. REALITY in Home Telecare: A Systemic Approach to Evaluation. 27th Annual International Conference of the Engineering in Medicine and Biology Society IEEEEMBS 2005;4:3927-3930.

10. Docobo. HealthHUB. c2008 [cited 2010 December 22]. Available from: http://www.docobo.co.uk/ArticlePage.aspx?articleld=7\&topParentld=7

11. DigiO 2 . Products - Care Pal Remote Patient Monitoring System. (2010a) c2010 [cited 2010 December 22]. Available from: http://www.digio2.com/product.php?item=16\&f item=1 
12. DigiO $2 . F A Q$ - Care Pal Remote Patient Monitoring System. (2010b) c2010 [cited 2010 December 22]. Available from: http://www.digio2.com/FAQ.php?item=2\&f item=1

13. FDA (Food and Drug Administration). Care Pal 510(k) Premarket Notification. (2010a). c2010 [updated 2010 July 12; cited 2010 December 22]. Available from: http://www.accessdata.fda.gov/scripts/cdrh/cfdocs/cfpmn/PMNSimpleSearch.cfm? $\mathrm{db}=P M N \& i d=K 091430$

14. Honeywell. Honeywell HomMed Genesis DM Remote Patient Care Monitor. c2010 [cited 2010 December 22]. Available from: http://www.hommed.com/Products/Genesis DM.asp

15. Home Telehealth Ltd. Honeywell Genesis DM remote patient care monitor. c2010 [cited 2010 December 22]. Available from: http://www.hometelehealthltd.co.uk/images/Honeywell\%20Genesis\%20datasheet.p df

16. Advantage HomeHealth Services. Honeywell HomMed Genesis ${ }^{T M}$ DM remote patient care monitor. c2007 [cited 2010 December 22]. Available from: http://www.advantagecarerehab.com/files/monitor.pdf

17. FDA (Food and Drug Administration). Honeywell Genesis OTC monitor, 510(k) Premarket Notification. (2010c). c2010 [updated 2010 July 12; cited 2010 December 22]. Available from: http://www.accessdata.fda.gov/scripts/cdrh/cfdocs/cfpmn/PMNSimpleSearch.cfm? $\underline{\mathrm{db}=P M N \& \mid \mathrm{D}=\mathrm{K} 061087}$

18. Intel. Intel Health Guide PHS6000 Product Brief. c2008 [cited 2010 December 22]. Available from: http://download.intel.com/healthcare/pdf/Health Guide Brief.pdf

19. Intel. Intel ${ }^{\circledR}$ Health Guide Overview. c2010 [cited 2010 December 22]. Available from: http://www.intel.com/healthcare/ps/healthguide/index.htm

20. FDA (Food and Drug Administration). MedApps 2.0 Remote Patient Monitoring System 510(k) Premarket Notification. (2010f). c2010 [updated 2010 July 12; cited 2010 December 22]. Available from: http://www.accessdata.fda.gov/scripts/cdrh/cfdocs/cfpmn/PMNSimpleSearch.cfm? $\underline{\mathrm{db}}=\mathrm{PMN \& id=K083862}$

21. Telehealth Solutions. Information Sheet, Home Pod. c2009 [cited 2010 December 22]. Available from: http://www.telehealthsolutions.co.uk/Downloads/HomePodPDFstyle1.pdf

22. Telehealth Solutions. Home Pod, What it does. c2010 [cited 2010 December 22]. Available from: http://www.telehealthsolutions.co.uk/products/home-pod/

23. Tunstall. Download video presentations. c2008 [cited 2010 December 22]. Available from: http://www.tunstallhealthcare.com/Download video presentation1962.aspx

24. Tunstall. Tunstall Telehealth Monitors. c2009 [cited 2010 December 22]. Available from: http://tunstallap.com/ assets/58-19-05-2009-09-27-10.pdf 
25. Tunstall. Telehealth. (2010a) c2010 [cited 2010 December 22]. Available from: http://www.tunstallap.com/products/Telehealth/10774/4

26. Tunstall. Tunstall Telehealth Solutions (2010b), c2010 [cited 2010 December 22]. [Online]. Available from: http://tunstallap.com/ assets/58-17-11-2009-08-45-17.pdf

27. FDA (Food and Drug Administration). RTX 3371, 510(k) Premarket Notification. (2010b). c2010 [updated 2010 July 12; cited 2010 December 28]. Available from: http://www.accessdata.fda.gov/scripts/cdrh/cfdocs/cfpmn/PMNSimpleSearch.cfm? $\underline{\mathrm{db}=P M N \& I D=K 090886}$

28. Tynetec. Telehealth Equipment. c2010 [cited 2010 December 22]. Available from: http://www.tynetec.co.uk/page/products

29. Hopp F P, Hogan MM, Woodbridge PA and Lowery JC. (2007). The use of telehealth for diabetes management: A qualitative study of telehealth provider perceptions. Implementation Science 2007;2:1

30. Ajai O, Tiwari A and Alcock JR. Evaluation of the state-of-the-art in informatics in glucometers. Informatics for Health and Social Care 2009;34:3:171-179

31. Adler Al, Stratton IM, Neil HAW, Yudkin JS, Matthews DR, Cull CA, Wright AD, Turner RC and Holman RR. Association of systolic blood pressure with macrovascular and microvascular complications of type 2 diabetes (UKPDS 36): prospective observational study. BMJ 2000;321:7258:412-419. 